Review

\title{
Disinfection of Water using Supported Titanium Dioxide Photocatalysts
}

\author{
${ }^{1 *}$ Shamkumar Pandurang Deshmukh, ${ }^{2}$ Dattatray Krishna Dalavi and ${ }^{3}$ Yuvaraj Mohan Hunge \\ ${ }^{* 1}$ Department of Chemistry, D.B.F. Dayanand College of Arts and Science, Solapur, India \\ ${ }^{2}$ Department of Chemistry, Bhogawati Mahavidyalaya, Kurukali, India \\ ${ }^{3}$ Photocatalysis International Research Centre, Tokyo University of Science, Chiba, Japan
}

\author{
Article history \\ Received: 31-10-2020 \\ Revised: 07-12-2020 \\ Accepted: 24-12-2020 \\ Corresponding Author: \\ Shamkumar Pandurang \\ Deshmukh \\ Department of Chemistry, \\ D.B.F. Dayanand College of \\ Arts and Science, Solapur, \\ India \\ Email: shamkumar0@gmail.com
}

\begin{abstract}
TiO}_{2}$ based photocatalyst has potential material for disinfection of harmful pathogens as well as removal of organic compounds. The formation of reactive oxygen species is a key part for overall process but aggregation and band gap constraint explore a new dimension to use of support for propounding its physicochemical properties. Therefore, the modification of $\mathrm{TiO}_{2}$ using various support alters photocatalytic action and promising ways of the mechanism based on nature of substrates and environments. In addition, the immobilization of nano dimension photocatalyst may reduce overall cost of operation and recovery of photocatalytic materials. In this perspective, extensive range of support materials as carbonaceous matters, clay, polymers, metal oxides have been studied by various researchers; that have been compiled in this review article. The properties of support were the key features for the assortment of appropriate supports for increase its efficiency as photocatalyst. In brief, overall $\mathrm{TiO}_{2}$ based photocatalyst supported on various substrates pave the ways toward new strategies for water disinfection.
\end{abstract}

Keywords: Photocatalyst, Water Disinfection, $\mathrm{TiO}_{2}$

\section{Introduction}

The world is continuously shifting into a new arena due to fast economic growth, industrial development and increasing population, but necessity of clean and pure water is excessive demand. On an average 1.2 billion people still shortage of pure water and diseases are spread due to contaminated water, which led to infant and child deaths (Catley-Carlson, 2017). Worldwide, around 502,000 people are died because of waterborne pathogenic bacteria and viruses (WHO, 2017).

The contamination of the water was increasing continuously due to industrial processes and urbanization in the natural water cycle. Therefore, there is need to reuse and recycle of water for the human being. In this regard, the various practices have been used for purification of water ( $\mathrm{Qu}$ and Fan, 2010, Deshmukh et al., 2013). In this perception, biological approaches were employed to remove the desired contaminates in the wastewater in the less time but formation of other pollutant was major constraint. Therefore, ecofriendly and viable methodologies are the key aspect for antimicrobial disinfection and water treatment with more prominent route (Deshmukh et al., 2019a-b).

Nowadays, as environmental viewpoint the photocatalysis and antimicrobial photoinactivation was grasping enormous consideration in the scientific world. In addition, it is increasing awareness due to poor quality of water that leads to various types' infections among the human being. The water treatment methods such as chlorination, ozonation have been used from the last few decades. These conventional treatment methods have a limitation as carcinogenic nature; formation of byproduct with mutation and non-economical process. Hence, there is need to develop new techniques, the advanced oxidation process is one of the ecofriendly method for the water treatment purpose; it has an ability to degrade water pollutants, heavy chemicals and generating environmental benign by-product (Saleh et al., 2020). Therefore, photocatalyst is the emerging area for the water disinfection as compared to the conventional water disinfection methods (Magalhaes et al., 2017). Photocatalyst is the process in which formation of reactive oxygen species and free radicals in the presence of light radiations; that could be useful for water disinfection. It has 
a capability to kill the microorganism without other chemicals and remove the pollutant in the water by photocatalytic process. Furthermore, cost of the process is lower and use of renewable energy sources as solar spectrum for photocatalysis process. Currently, various semiconducting materials as $\mathrm{ZrO}_{2}, \mathrm{Fe}_{2} \mathrm{O}_{3}, \mathrm{WO}_{3}, \mathrm{ZnO}, \mathrm{CdSe}$ used for the same but among these $\mathrm{TiO}_{2}$ is the foremost advantages as cost effective, chemically stable, non-toxic with higher quantum efficiency (Patil et al., 2017; 2019).

The antimicrobial activity of $\mathrm{TiO}_{2}$ was reported (Matsunaga et al., 1985) by for inactivation of bacteria. $\mathrm{TiO}_{2}$ shows the three phases as anatase, rutile and brookite. In which, rutile phase is more stable but anatase phase is extensively used during photocatalysis process because of ease to prepare and better activity. Brookite is compared to least stability and less used in photocatalysis. In addition, the various types of photocatalytic materials have used for wide range of antimicrobial events against the viruses, bacteria, fungi and algae (You et al., 2019). The photocatalytic activity was depend on the process of photo-excitation by visible, UV or near infra-red light radiation based on band gaps. The band gaps of $\mathrm{TiO}_{2}$ are relying upon the preparation methods, formation of defects and phases. The band gap of $\mathrm{TiO}_{2}$ is 3.2 and $3.0 \mathrm{eV}$ for anatase and rutile phases respectively (Mills and Le Hunte, 1997).

The role of $\mathrm{TiO}_{2}$ as photocatalyst is effective in the UV region, so there is need to tune their band gap in the visible region. The visible light active material is effective for the bacterial inactivation. The various strategies have been used for effective antimicrobial purpose (You et al., 2019). Among these strategies the $\mathrm{TiO}_{2}$ supported catalyst are effective path for the water disinfection. The different methodology have efficiently employed to immobilize catalyst on various supporting materials as a glass material, metals, zeolites, Chitosan, Cellulose, etc. (Srikanth et al., 2017, Chen et al., 2010). The wide dimensions of support were useful for the photocatalyst. In addition, photocatalytic activity was executed by using the proper wavelength of light. This review compiles the titanium dioxide supported photocatalyst for the water disinfection.

\section{Mechanism of Photocatalytic Antimicrobial Inactivation}

An environment is surrounded by wide range of the pathogenic microorganism; this is major reason of diseases for typhoid, cholera and illness as the flu and cold, etc. These diseases transfer via aerosol particles, surfaces, agriculture product and water. Last few decades, we are facing a problem of water purification so that $\mathrm{TiO}_{2}$ based photocatalyst is effective strategy for the bacterial inactivation. Besides disinfection of water, it is a very effective process that can be used to diminish water contaminate, odour of water. Photocatalyst is the process in which formation of electron-hole pairs in the presence of light radiation. Sufficient amount of light radiation is irradiated on the photocatalytic material and it is higher energy as compared to the band gap of $\mathrm{TiO}_{2}$ materials. The electron is excited from Valence Band (VB) to Conduction Band (CB) that lead to hole formation at $\mathrm{VB}$ of photocatalyst. These electrons- hole pair's reaches to surface of the catalyst and carrying out redox reactions. These charged particles are responsible for the formation of reactive oxygen species.

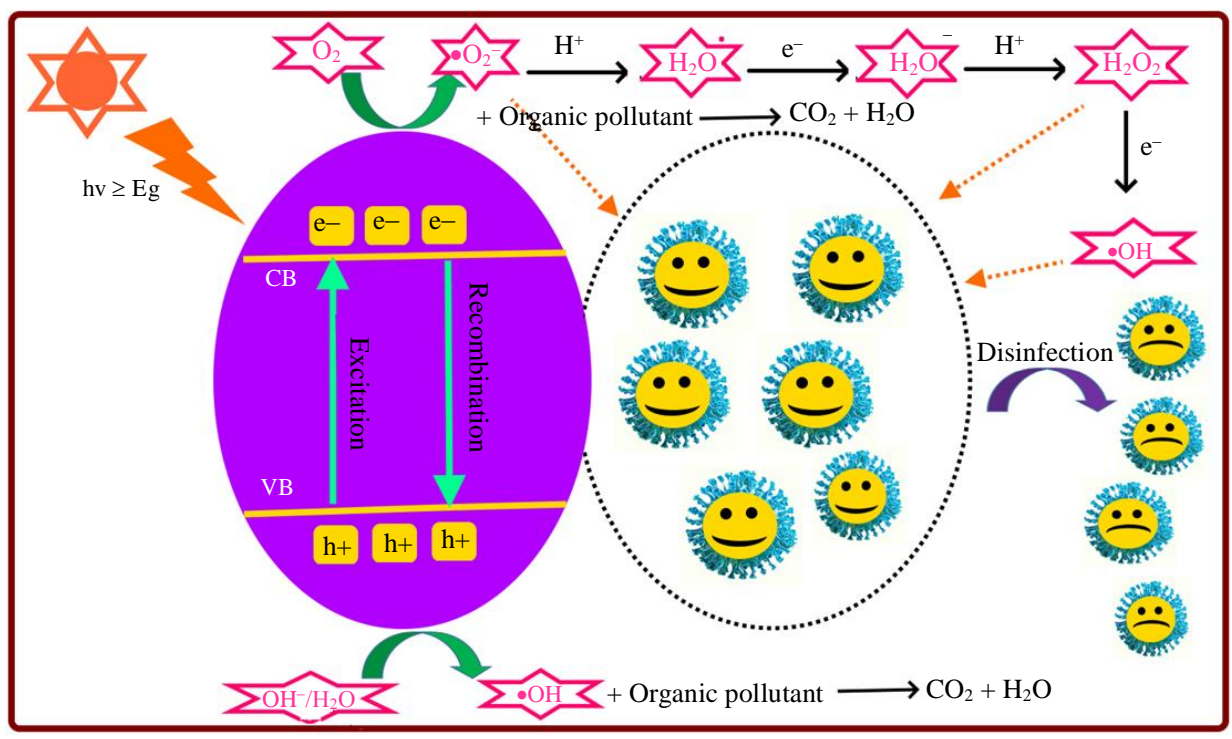

Fig. 1: Photocatalytic disinfection and pollutant degradation mechanism 
The redox process leads to formation of reactive oxygen species which can reduces oxygen molecules and generating $\mathrm{O}_{2}^{-}$, ${ }^{\circ} \mathrm{OH}$ and $\mathrm{H}_{2} \mathrm{O}_{2}$. These species damage the cell wall of the microbes, viruses and changes permeability of cell and increase stress on the cell. It also inhibited proteins actions that are useful for the biological process of the cell (Koli et al., 2020). Photocatalytic inactivation process of viruses and organic pollutant by the different reactive oxygen process is shown in the Fig. 1. The oxidative stress is another cause to generate pyrimidine dimers in the DNA. Such changes in the structure of DNA pave the ways towards improper working of the cell and finally cell death. Furthermore, RNA is also more sensitive to photocatalyst than DNA in vivo and vitro circumstances (Pigeot-Rémy et al., 2011).

\section{Necessity of Supported Titanium Dioxide}

In the water treatment process the Degussa $\mathrm{P}-25 \mathrm{TiO}_{2}$ was normally used as photocatalyst. It is very efficient semiconducting material as compared to other reported photocatalytic materials. Degussa P-25 $\mathrm{TiO}_{2}$ was the in the form of fine particles having ability to form reactive oxygen species as relative to surface particles in the dispersed phase. On the other hand, when it was incorporated on the inert surfaces, it would diminish dynamic spots and mass transfer drawbacks. It has also problems with formation of reactive oxygen species leads to decrease in photocatalytic activity (Pozzo et al., 1997). The post-treatment path is important part of separation of the catalyst, in which decreasing amount of the catalyst and introducing of a new pollutant during the process water treatment using $\mathrm{TiO}_{2}$ is the crucial challenges (Yang and Cheng, 2007). The major problem was retrieval of catalyst from the solution, controlling $\mathrm{pH}$ of the solution and other membrane obstruction and fouling. To improve catalytic properties there is need to use supporting materials to overcome this limitation as reusability of the catalyst, increasing active hotspot of catalyst to increase their activity.

As the solar energy is abundant in the nature but only $3-4 \%$ of UV light radiation has been used for the photocatalytic process for the bare $\mathrm{TiO}_{2}$. The average $43 \%$ of visible light radiations are useful for the photocatalytic activity. The major limitation of $\mathrm{TiO}_{2}$ is unable use visible light spectrum for photocatalytic activity, therefore tuning or optimizing $\mathrm{TiO}_{2}$ into the visible light radiation is better route for increasing efficiency for the disinfection (Deshmukh et al., 2019a). In the literature, various routes have been used such as doping, metallization, sensitization and supporting material. Among them supported metal nanoparticles have more efficient for bacterial inactivation that other; therefore herein we reported $\mathrm{TiO}_{2}$ supported metal nanoparticles (Chen et al., 2010, Mohite et al., 2015). Therefore, carbonaceous matters, clay and ceramics, polymers, metal oxides are used as supporting material for the $\mathrm{TiO}_{2}$.

\section{Polymers}

The efficiency of the catalyst is depends on its nature and type of support and at ease between $\mathrm{TiO}_{2}$ and support for appropriate combination for better catalytic activity. In all other support polymer is used because of their some remarkable advantages. Thermoplastic nature of the polymer has thermoplastic properties which are useful for the simple coating on $\mathrm{TiO}_{2}$ using simple way (Singh et al., 2013). Polymers are stable and inert in nature with the long life spans. The adsorption ability of $\mathrm{TiO}_{2}$ was improved due to polymer support with hydrophobic nature. Such nature of the polymer exhibits the effective support material for the photocatalysis process (Reddy et al., 2020). The incorporation of metal oxides with polymers led to formation of composites with improved thermal, electrical and rheological properties. The polymer support is playing important role for recovery of catalyst and multiple use of photocatalyst. Among the various conducting polymers as polyaniline, polypyrrole and polythiophene and their by-products were effective to shift of UV light to visible light spectrum to improve quantum efficiency of $\mathrm{TiO}_{2}$ photocatalyst. Polyaniline is photosensitizer and economical, stable and better electrical conducting ability (Tamboli et al., 2013). The polyaniline/titanium dioxide nanocomposites reduces bacterial growth of $E$. coli pathogenic organism and effective for the dye degradation also (Jeong et al., 2014). $\mathrm{PANI} \mathrm{TiO}_{2}$ is auspicious adsorbent and ability to remove more than $70 \%$ of biopolymer from secondary effluent. It also having very less antifouling activity analogous with less quantity of foulants. Furthermore, setup cost was less and majorly effective for advances on water quality (Li et al., 2020b). Porous Polymethyl Methacrylate (PMMA) substrates was employed to immobilize $\mathrm{TiO}_{2}$ nanoparticles in the fiber forms and efficiently used for degradation of methylene blue. The photocatalytic performances were analyzed by optimizing fiber porosity and its architecture with higher surface area (Kanth et al., 2020). The poly (acrylonitrile) supported carbon doped titanium dioxide nanocomposite was developed by sol-gel method and immobilize by phase inversion route. Thereafter, methyl orange and golden yellow textile dyes was degraded using this nanocomposites (Mpelane et al., 2020).

\section{Carbonaceous Materials}

Carbonaceous materials are another class of the materials useful for supporting purpose due to their 
admirable properties. Basically, carbonaceous materials are better chemical stability, optimized structural and optical properties and increased surface to volume ratio, better mobility of charges particles. Carbonaceous materials are consisting of carbon nanotubes, activated carbon, graphene and graphitic carbon nitride. The carbon based materials are efficient for adsorption of the pollutants or other contaminated chemicals in the water; it is also enhances the active surface of the catalyst and act as effective photocatalyst (Sakthivel and Kisch, 2003). Several researchers are reported that quantum efficiency of $\mathrm{TiO}_{2}$ may be increased using carbonaceous materials in the visible spectrum as associated to pure $\mathrm{TiO}_{2}$, it is because of chemical linkage between them (Silva et al., 2020). $\mathrm{TiO}_{2}$ was coated on the carbon foam act as effective treatment for degradation of dye present in the wastewater under the solar spectrum. The $3 \mathrm{D}$ outline of foam was upgraded for increasing thermal stability and avoids particles agglomeration. Photocatalytic capacity of the catalyst was increased due to light absorption of nitrogen based foam and better charge carrier separation (Lu et al., 2020). Mesones et al. (2020) reported the photo-electrocatalytic activity of $\mathrm{TiO}_{2}$ supported on activated carbon for water disinfection using $3 \mathrm{D}$ bipolar electrodes. The electrocatalytic activity can generates the chlorine and hydroxyl radicals lead to synergic effect for water disinfection process. Polymer binder is used as produce char which is act as structural support of $\mathrm{TiO}_{2}$ to conquer mechanical stability and diminish aggregation. The carbonaceous char was co-exist with $\mathrm{TiO}_{2}$ and enhanced physicochemical properties lead to higher photocatalytic activity for acid orange 7 dyes under ultraviolet light. (Wang et al., 2016). Carbon-supported $\mathrm{TiO}_{2}$ was prepared using hydrothermal route to study its adsorption ability and photocatalytic activity against phenol, naphthol blue black and reactive black in the presence of UV radiation (Nguyen et al., 2020).

\section{Clays}

Clays are an enclosed phyllosilicate mineral that arises naturally in the earth's crust and significant ingredients of the soils. Clay have astonishing properties as surface activity, better adsorption ability, cation exchange, swelling and biocompatibility which provides them as alternative material for wide-range of applications. Clay minerals are rich in environment and ease to modify to increase efficiency for water disinfection (Mishra et al., 2018). The proper mixing of clay and photocatalytic materials as $\mathrm{TiO}_{2}$ may improve efficiency pave the way towards the better material for removal of toxic chemicals and pathogens from the water and act as active water disinfectant. Fig. 2. represent the water disinfection process using $\mathrm{TiO}_{2}$ as photocatalyst. In which, the representative type of dyes were degraded as well as killing of pathogenic microbes was presented. Water disinfection was carried out using physical, chemical and biological process; while each process has some advantages and disadvantages. Therefore, use of photocatalytic material with clays as support for nanosize semiconducting materials may useful to improve their catalytic activity as analogous to bare materials. In this context, wide range of clay such as kaolinite, bentonite and montmorillonite were used as excellent support (Mustapha et al., 2020). Dalai et al. (2014) reported chemical interaction between adsorbent $\mathrm{TiO}_{2}$ with bacteria using XPS techniques and it also reveals that formation of charge carries were responsible for the damage of the cell wall.

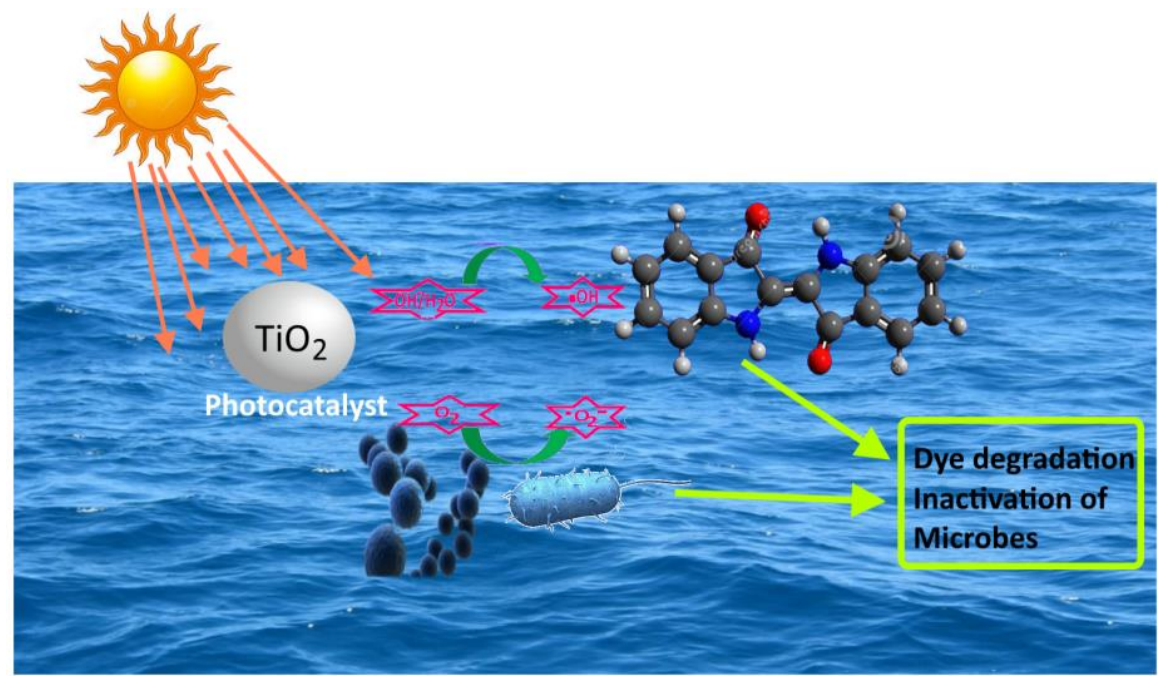

Fig. 2: The water disinfection process 


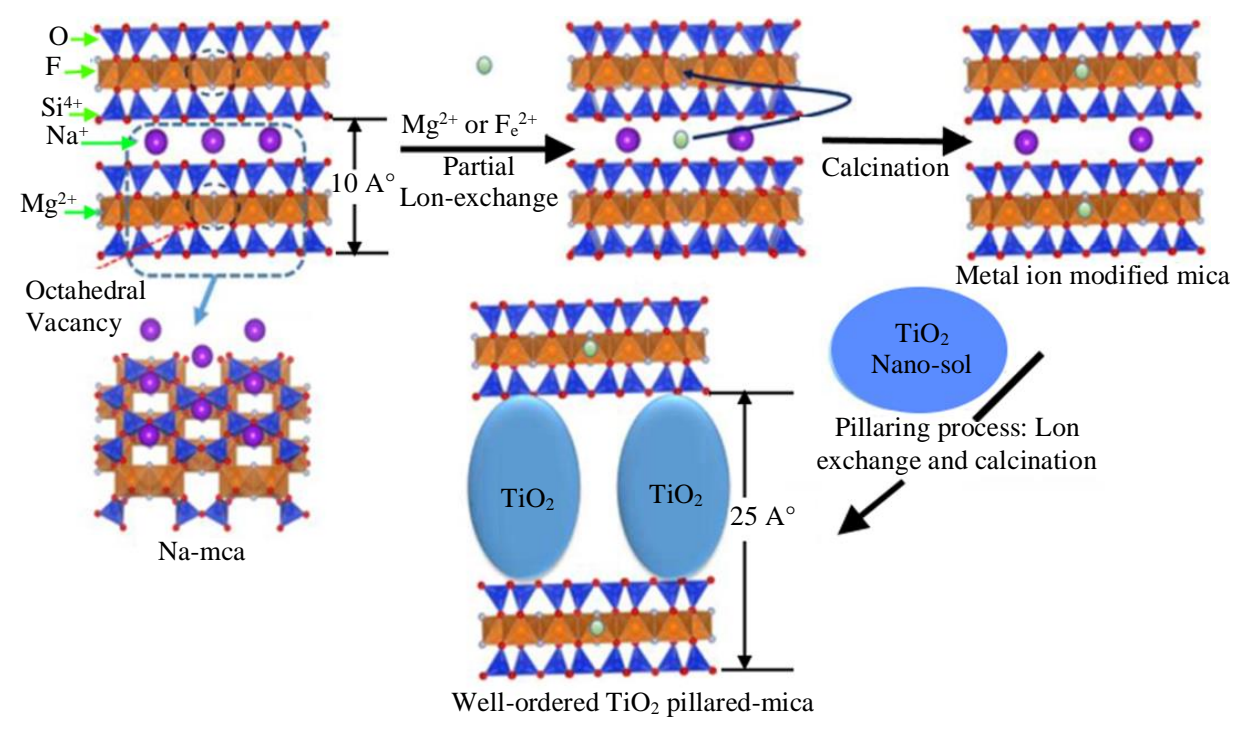

Fig. 3: Synthesis of well-ordered $\mathrm{TiO}_{2}$ pillared clay

$\mathrm{TiO}_{2}$ pillared clays with spongy structure were prepared through combining $\mathrm{TiO}_{2}$ nano-sol elements into the clays. It exhibits better photocatalytic activity against the methyl orange in the presence of UV radiation (Yang et al., 2015). Figure 3 shows the well-ordered $\mathrm{TiO}_{2}$ pillar clay.

Micro-fibrous palygorskite and halloysite clay inorganic incorporate with $\mathrm{TiO}_{2}$ and coated on the glass surfaces to avoid aggregation of $\mathrm{TiO}_{2}$. These composites were better efficacy as photocatalyst for the water disinfection (Panagiotaras et al., 2014). Clay- $\mathrm{TiO}_{2}$ nanocomposites were synthesis using biomass supported the process for the removal of antibiotics such as ampicillin, sulfamethoxazole and artemether consisting in the water. Surface active oxygen vacancies and charge particles and defect present in the crystal lattice playing crucial role of photocatalytic activity for water disinfection (Alfred et al., 2020).

\section{Metal Oxides}

Improved $\mathrm{TiO}_{2}$ can increase their photocatalytic action using the various mechanisms, consisting of decreasing band gap of such materials; it also reduces recombination of the electron-hole combination. Contemporary year's metal and metal oxides have been used as support for the $\mathrm{TiO}_{2}$ to increase photocatalytic efficiency and water disinfection ability. Metal supported $\mathrm{TiO}_{2}$ with antibacterial activity in the presence of UV/Visible and dark condition were analyzed with higher antibacterial activity due to strong interconnectivity between Ti-O-Ag bonds (Deshmukh et al., 2018). Li et al. (2020a) reported the modification of $\mathrm{TiO}_{2}$ using various routes for water treatment. In addition, the various materials such as glass, clay, metal oxides act as support for the $\mathrm{TiO}_{2}$ useful for water treatment. While some metal contaminates are also major reason for reduction in the photocatalytic activity. $\mathrm{WO}_{3} / \mathrm{TiO}_{2}$ based heterostructure has been used for removal of Rhodamine $B$ and Reactive red dye from the wastewater in the presence of sunlight radiation. The crystalline nature, better optical properties and without mixed phases were the key properties for competent photocatalytic activity in the visible light ratiation (Hunge et al., 2018a-b). Mahlambi et al. (2015) reported the recent development in $\mathrm{TiO}_{2}$ nanocatalysts were playing major role for environmental remediation as removal of the pollutant from the water bodies. Furthermore, the roles of $\mathrm{TiO}_{2}$ nanoparticles act as accompanying and analogous to water processing technologies in which, the conversion of toxic chemicals into the oxides of carbon and water molecules. Shi et al. (2018) reported recyclable light and heat assisted route for removal of the pollutant from the wastewater system. The $\mathrm{TiO}_{2}$ supported on $\mathrm{Fe}_{3} \mathrm{O}_{4}$ nanoparticles was revealed the enhanced proficiency for Rhodamine B dye degradation in the wastewater treatment. In addition, the magnetic properties of the materials was also astonishing properties; hence it can be easily separable and reuse consistently. Jia et al. (2016) reported $\mathrm{TiO}_{2}-\mathrm{Bi}_{2} \mathrm{WO}_{6}$ binanosheet prepared using hydrothermal route and used as capable material for visible light active photocatalyst for inactivation of $E$. coli pathogenic bacteria. The electron and hole were playing major roles in photocatalytic disinfection. In which, leakage of the cell as DNA and protein lead to damage of the cell membrane was observed. The better separation of the charge carrier is useful for the disinfection process. Table 1 represents the various types of substrate used as support and synthesis protocol and water disinfection as pollutants or microbes. 
Table 1: A comparative overview of $\mathrm{TiO}_{2}$ and its support for disinfection process

\begin{tabular}{|c|c|c|c|c|}
\hline Catalyst & substrate & Method of synthesis & Microbes/pollutants & References \\
\hline $\mathrm{TiO}_{2}$ & PANI & chemical polymerization & Secondary effluent & Li et al. (2020a) \\
\hline $\mathrm{TiO}_{2}$ & PANI & chemical polymerization & methylene blue, E. coli & Jeong et al. (2014) \\
\hline $\mathrm{TiO}_{2}$ & PMMA & wet phase inversion & Methylene blue & Kanth et al. (2020) \\
\hline $\mathrm{TiO}_{2}$ & Poly acrylonitrile & sol-gel method & methyl orange and golden yellow & Mpelane et al. (2020) \\
\hline $\mathrm{TiO}_{2}$ & Activated Carbon & impregnation method & E. coli & Mesones et al. (2020) \\
\hline $\mathrm{TiO}_{2}$ & Carbonaceous char & spinning-pyrolysis & Acid orange 7 & Wang et al. (2016) \\
\hline $\mathrm{TiO}_{2}$ & Activated carbon & hydrothermal process & $\begin{array}{l}\text { phenol, Naphthol Blue Black (NBB) } \\
\text { and Reactive Black } 5 \text { (RB5) }\end{array}$ & Nguyen et al. (2020) \\
\hline $\mathrm{TiO}_{2}$ & $\begin{array}{l}\text { Microfibrous palygorskite } \\
\text { and tubular halloysite }\end{array}$ & sol-gel method & Basic blue 41 azo dye & Panagiotaras et al. (2014) \\
\hline $\mathrm{TiO}_{2}$ & kaolinite clay & biomass assisted synthesis & $\begin{array}{l}\text { ampicillin, sulfamethoxazole } \\
\text { and artemether }\end{array}$ & Alfred et al. (2020) \\
\hline $\mathrm{TiO}_{2}$ & cationic clays & ion-exchange reaction & methyl orange & Yang et al. (2015) \\
\hline $\mathrm{TiO}_{2}$ & $\mathrm{Fe}_{3} \mathrm{O}_{4}$ & Chemical reduction method & Rhodamine B & Shi et al. (2018) \\
\hline $\mathrm{TiO}_{2}$ & $\mathrm{Bi}_{2} \mathrm{WO}_{6}$ & hydrothermal method & E. coli & Jia et al. (2016) \\
\hline
\end{tabular}

\section{Conclusions}

This review highlights the properties and different types $\mathrm{TiO}_{2}$ supported materials used as photocatalyst for the water disinfection process. The photocatalytic activity based $\mathrm{TiO}_{2}$ supported materials new approaches for the water disinfection. In addition, the metal supported materials were optimized by tuning the structural and optical properties to use a wide range of the solar spectrum. The various supports such as carbonaceous materials, polymers, clay and metal oxide were used to improve its physicochemical properties of $\mathrm{TiO}_{2}$. Moreover, there is more scope for enhancement of this technology as a photocatalytic material design, overall operation process and so on. The key factor is using of not only UV but also visible range, i.e., wide range of the solar spectrum. In addition, in waste water containing a wide range of the pathogenic microorganism, numbers of dyes which are degrading completely and remove the pathogenic microorganism are the key challenge of human being yet to resolve.

\section{Acknowledgement}

SPD would like to thanks D.B.F. Dayanand College of Arts and Science, Solapur for financial and technical support.

\section{Author's Contributions}

Shamkumar Pandurang Deshmukh: Lead role of writing and completing the paper.

Dattatray Krishna Dalavi: Revising data of review article.

Yuvaraj Mohan Hunge: Supporting and rewriting.

\section{Ethics}

This article is original and contains unpublished material. The corresponding author confirms that all of the other authors have read and approved the manuscript and no ethical issues involved.

\section{References}

Alfred, M. O., Omorogie, M. O., Bodede, O., Moodley, R., Ogunlaja, A., Adeyemi, O. G., ... \& Silva, I. D. (2020). Solar-Active Clay-TiO ${ }_{2}$ Nanocomposites Prepared via Biomass Assisted Synthesis: Efficient Removal of Ampicillin, Sulfamethoxazole and Artemether in Water. Chemical Engineering Journal, 125544.

Catley-Carlson, M. (2017). Water supply: The emptying well. Nature, 542(7642), 412-413.

Chen, X., Zheng, Z., Ke, X., Jaatinen, E., Xie, T., Wang, D., ... \& Zhu, H. (2010). Supported silver nanoparticles as photocatalysts under ultraviolet and visible light irradiation. Green Chemistry, 12(3), 414-419.

Dalai, S., Pakrashi, S., Chakravarty, S., Hussain, S., Chandrasekaran, N., \& Mukherjee, A. (2014). Studies on interfacial interactions of $\mathrm{TiO}_{2}$ nanoparticles with bacterial cells under light and dark conditions. Bulletin of materials science, 37(3), 371-381.

Deshmukh, S. P., Dhodamani, A. G., Patil, S. M., Mullani, S. B., More, K. V., \& Delekar, S. D. (2019a). Interfacially Interactive Ternary SilverSupported Polyaniline/Multiwalled Carbon Nanotube Nanocomposites for Catalytic and Antibacterial Activity. ACS omega, 5(1), 219-227.

Deshmukh, S. P., Patil, S. M., Mullani, S. B., \& Delekar, S. D. (2019b). Silver nanoparticles as an effective disinfectant: A review. Materials Science and Engineering: C, 97, 954-965.

Deshmukh, S. P., Dhokale, R. K., Yadav, H. M., Achary, S. N., \& Delekar, S. D. (2013). Titania-supported silver nanoparticles: An efficient and reusable catalyst for reduction of 4-nitrophenol. Applied surface science, 273, 676-683. 
Deshmukh, S. P., Mullani, S. B., Koli, V. B., Patil, S. M., Kasabe, P. J., Dandge, P. B., ... \& Delekar, S. D. (2018). Ag nanoparticles connected to the surface of $\mathrm{TiO}_{2}$ electrostatically for antibacterial photoinactivation studies. Photochemistry and Photobiology, 94(6), 1249-1262.

Hunge, Y. M., Yadav, A. A., Mahadik, M. A., Bulakhe, R. N., Shim, J. J., Mathe, V. L., \& Bhosale, C. H. (2018a). Degradation of organic dyes using spray deposited nanocrystalline stratified $\mathrm{WO}_{3} / \mathrm{TiO}_{2}$ photoelectrodes under sunlight illumination. Optical Materials, 76, 260-270.

Hunge, Y. M., Yadav, A. A., Mahadik, M. A., Mathe, V. L., \& Bhosale, C. H. (2018b). A highly efficient visible-light responsive sprayed WO3/FTO photoanode for photoelectrocatalytic degradation of brilliant blue. Journal of the Taiwan Institute of Chemical Engineers, 85, 273-281.

Jeong, W. H., Amna, T., Ha, Y. M., Hassan, M. S., Kim, H. C., \& Khil, M. S. (2014). Novel PANI nanotube@ $\mathrm{TiO}_{2}$ composite as efficient chemical and biological disinfectant. Chemical Engineering Journal, 246, 204-210.

Jia, Y., Zhan, S., Ma, S., \& Zhou, Q. (2016). Fabrication of $\mathrm{TiO}_{2}-\mathrm{Bi}_{2} \mathrm{WO}_{6}$ binanosheet for enhanced solar photocatalytic disinfection of $E$. coli: insights on the mechanism. ACS applied materials \& interfaces, 8(11), 6841-6851.

Kanth, N., Xu, W., Prasad, U., Ravichandran, D., Kannan, A. M., \& Song, K. (2020). PMMA-TiO Fibers for the Photocatalytic Degradation of Water Pollutants. Nanomaterials, 10(7), 1279.

Koli, V. B., Ke, S. C., Dodamani, A. G., Deshmukh, S. P., \& Kim, J. S. (2020). Boron-Doped $\mathrm{TiO}_{2}-\mathrm{CNT}$ Nanocomposites with Improved Photocatalytic Efficiency toward Photodegradation of Toluene Gas and Photo-Inactivation of Escherichia coli. Catalysts, 10(6), 632.

Li, R., Li, T., \& Zhou, Q. (2020a). Impact of titanium dioxide $\left(\mathrm{TiO}_{2}\right)$ modification on its application to pollution treatment-a review. Catalysts, 10(7), 804.

Li, X., Tang, G., Zhang, D., Wu, L., Lu, S., Zhang, Y., ... \& Pan, B. (2020b). Fouling control in ultrafiltration of secondary effluent using polyaniline/ $/ \mathrm{TiO}_{2}$ adsorption and subsequent treatment of desorption eluate using electrochemical oxidation. Chemical Engineering Journal, 382, 122915.

Lu, X., Li, Z., Liu, Y. A., Tang, B., Zhu, Y., Razal, J. M., ... \& Wang, X. (2020). Titanium dioxide coated carbon foam as microreactor for improved sunlight driven treatment of cotton dyeing wastewater. Journal of Cleaner Production, 246, 118949.

Magalhaes, P., Andrade, L., Nunes, O. C., \& Mendes, A. (2017). Titanium dioxide photocatalysis: Fundamentals and application on photoinactivation. Reviews on Advanced Materials Science, 51(2).
Mahlambi, M. M., Ngila, C. J., \& Mamba, B. B. (2015). Recent developments in environmental photocatalytic degradation of organic pollutants: the case of titanium dioxide nanoparticles-a review. Journal of Nanomaterials, 790173.

Matsunaga, T., Tomoda, R., Nakajima, T. \& Wake, H. (1985). Photoelectrochemical sterilization of microbial cells by semiconductor powders. FEMS Microbiol. Lett., 29, 211-214.

Mesones, S., Mena, E., Muñoz, M. J. L., Adán, C., \& Marugán, J. (2020). Synergistic and antagonistic effects in the photoelectrocatalytic disinfection of water with $\mathrm{TiO}_{2}$ supported on activated carbon as a bipolar electrode in a novel 3D photoelectrochemical reactor. Separation and Purification Technology, 117002.

Mills, A., \& Le Hunte, S. (1997). An overview of semiconductor photocatalysis. Journal of photochemistry and photobiology A: Chemistry, 108(1), 1-35.

Mishra, A., Mehta, A., \& Basu, S. (2018). Clay supported $\mathrm{TiO}_{2}$ nanoparticles for photocatalytic degradation of environmental pollutants: A review. Journal of environmental chemical engineering, 6(5), 6088-6107.

Mohite, V. S., Mahadik, M. A., Kumbhar, S. S., Hunge, Y. M., Kim, J. H., Moholkar, A. V., ... \& Bhosale, C. H. (2015). Photoelectrocatalytic degradation of benzoic acid using $\mathrm{Au}$ doped $\mathrm{TiO}_{2}$ thin films. Journal of Photochemistry and Photobiology B: Biology, 142, 204-211.

Mpelane, A., Katwire, D. M., Mungondori, H. H., Nyamukamba, P., \& Taziwa, R. T. (2020). Application of Novel $\mathrm{C}_{-} \mathrm{TiO}_{2}-\mathrm{CFA} / \mathrm{PAN}$ Photocatalytic Membranes in the Removal of Textile Dyes in Wastewater. Catalysts, 10(8), 909.

Mustapha, S., Ndamitso, M. M., Abdulkareem, A. S., Tijani, J. O., Shuaib, D. T., Ajala, A. O., \& Mohammed, A. K. (2020). Application of $\mathrm{TiO}_{2}$ and $\mathrm{ZnO}$ nanoparticles immobilized on clay in wastewater treatment: a review. Applied Water Science, 10(1), 1-36.

Nguyen, C. H., Tran, H. N., Fu, C. C., Lu, Y. T., \& Juang, R. S. (2020). Roles of adsorption and photocatalysis in removing organic pollutants from water by activated carbon-supported titania composites: Kinetic aspects. Journal of the Taiwan Institute of Chemical Engineers.

Panagiotaras, D., Papoulis, D., \& Stathatos, E. (2014). $\mathrm{TiO}_{2} / \mathrm{Clay}$ Minerals (Palygorskite/Halloysite) Nanocomposite Coatings for Water Disinfection. International Journal of Materials and Metallurgical Engineering, 8(3), 180-187. 
Patil, S. M, P Deshmukh, S., G Dhodamani, A., V More, K., \& D Delekar, S. (2017). Different Strategies for Modification of Titanium Dioxide as Heterogeneous Cata lyst in Chemical Transformations. Current Organic Chemistry, 21(9), 821-833.

Patil, S. M., Deshmukh, S. P., More, K. V., Shevale, V. B., Mullani, S. B., Dhodamani, A. G., \& Delekar, S. D. (2019). Sulfated $\mathrm{TiO}_{2} / \mathrm{WO}_{3}$ nanocomposite: An efficient photocatalyst for degradation of Congo red and methyl red dyes under visible light irradiation. Materials Chemistry and Physics, 225, 247-255.

Pigeot-Rémy, S., Simonet, F., Errazuriz-Cerda, E., Lazzaroni, J. C., Atlan, D., \& Guillard, C. (2011). Photocatalysis and disinfection of water: identification of potential bacterial targets. Applied Catalysis B: Environmental, 104(3-4), 390-398.

Pozzo, R. L., Baltanas, M. A., \& Cassano, A. E. (1997). Supported titanium oxide as photocatalyst in water decontamination: state of the art. Catalysis Today, 39(3), 219-231.

Qu, J., \& Fan, M. (2010). The current state of water quality and technology development for water pollution control in China. Critical reviews in environmental science and technology, 40(6), 519-560.

Reddy, K. R., Jyothi, M. S., Raghu, A. V., Sadhu, V., Naveen, S., \& Aminabhavi, T. M. (2020). Nanocarbons-supported and polymers-supported titanium dioxide nanostructures as efficient photocatalysts for remediation of contaminated wastewater and hydrogen production. In Nanophotocatalysis and Environmental Applications (pp. 139-169). Springer, Cham.

Sakthivel, S., \& Kisch, H. (2003). Daylight photocatalysis by carbon-modified titanium dioxide. Angewandte Chemie International Edition, 42(40), 4908-4911.

Saleh, I. A., Zouari, N., \& Al-Ghouti, M. A. (2020). Removal of pesticides from water and wastewater: Chemical, physical and biological treatment approaches. Environmental Technology \& Innovation, 101026.

Shi, L., He, Y., Wang, X., \& Hu, Y. (2018). Recyclable photo-thermal conversion and purification systems via $\mathrm{Fe} 3 \mathrm{O} 4 @ \mathrm{TiO}_{2}$ nanoparticles. Energy conversion and management, 171, 272-278.
Silva, M. R., Lourenço, M. A., Tobaldi, D. M., da Silva, C. F., Seabra, M. P., \& Ferreira, P. (2020). Carbonmodified titanium oxide materials for photocatalytic water and air decontamination. Chemical Engineering Journal, 387, 124099.

Singh, S., Mahalingam, H., \& Singh, P. K. (2013). Polymer-supported titanium dioxide photocatalysts for environmental remediation: A review. Applied Catalysis A: General, 462, 178-195.

Srikanth, B., Goutham, R., Narayan, R. B., Ramprasath, A., Gopinath, K. P., \& Sankaranarayanan, A. R. (2017). Recent advancements in supporting materials for immobilised photocatalytic applications in waste water treatment. Journal of environmental management, 200, 60-78.

Tamboli, M. S., Kulkarni, M. V., Deshmukh, S. P., \& Kale, B. B. (2013). Synthesis and spectroscopic characterisation of silver-polyaniline nanocomposite. Materials Research Innovations, 17(2), 112-116.

Wang, D. K., Elma, M., Motuzas, J., Hou, W. C., Schmeda-Lopez, D. R., Zhang, T., \& Zhang, X. (2016). Physicochemical and photocatalytic properties of carbonaceous char and titania composite hollow fibers for wastewater treatment. Carbon, 109, 182-191.

WHO. (2017). Progress on drinking water, sanitation and hygiene: 2017 update and SDG baselines.

Yang, H., \& Cheng, H. (2007). Controlling nitrite level in drinking water by chlorination and chloramination. Separation and Purification Technology, 56(3), 392-396.

Yang, J. H., Piao, H., Vinu, A., Elzatahry, A. A., Paek, S. M., \& Choy, J. H. (2015). TiO 2 -pillared clays with well-ordered porous structure and excellent photocatalytic activity. RSC advances, 5(11), 8210-8215.

You, J., Guo, Y., Guo, R., \& Liu, X. (2019). A review of visible light-active photocatalysts for water disinfection: Features and prospects. Chemical Engineering Journal, 373, 624-641. 